\title{
Feature parsing: Feature cue mapping in spoken word recognition
}

\author{
DAVID W. GOW, JR. \\ Massachusetts General Hospital, Boston, Massachusetts \\ and Salem State College, Salem, Massachusetts
}

\begin{abstract}
For listeners to recognize words, they must map temporally distributed phonetic feature cues onto higher order phonological representations. Three experiments are reported that were performed to examine what information listeners extract from assimilated segments (e.g., place-assimilated tokens of cone that resemble comb) and how they interpret it. Experiment 1 employed form priming to demonstrate that listeners activate the underlying form of CONE, but not of its neighbor (COMB). Experiment 2 employed phoneme monitoring to show that the same assimilated tokens facilitate the perception of postassimilation context. Together, the results of these two experiments suggest that listeners recover both the underlying place of the modified item and information about the subsequent item from the same modified segment. Experiment 3 replicated Experiment 1, using different postassimilation contexts to demonstrate that context effects do not reflect familiarity with a given assimilation process. The results are discussed in the context of general auditory grouping mechanisms.
\end{abstract}

The phonetic features that define any phoneme are encoded in the speech signal by a set of acoustic cues distributed and often defined over time. Moreover, each individual feature is typically recovered by integrating multiple distributed cues (Bailey \& Summerfield, 1980; Summerfield \& Haggard, 1977). Although feature cues are realized along an acoustic continuum, the abstract feature values that listeners derive from them are generally viewed as discrete. In this paper, I use the phenomenon of English coronal place assimilation to explore the distribution of feature cues across the speech signal and the processes that listeners use to align and map them onto discrete sequential representations.

\section{Feature Parsing}

Most psycholinguistic models of word recognition share the premise that segments are defined by a matrix of feature values (Marslen-Wilson, 1987; McClelland \& Elman, 1986; Norris, 1994; Norris, McQueen, \& Cutler, 2000). These models assume that there is a one-to-one linear association between features and segments. This view of association is at odds with the central tenets of autosegmental phonology (Goldsmith, 1976). Phonologists argue that a variety of phonological phenomena, including

This research was supported by Grant R29DC03108 to the Massachusetts General Hospital (D.W.G., Principal Investigator) from the National Institutes of Health. I thank David Caplan, Stefanie ShattuckHufnagel, Cheryl Zoll, and an anonymous reviewer for their invaluable feedback and generous encouragement of this work and Carrie Landa and Aaron Im for their assistance in carrying out the experiments. Please direct correspondence concerning this article to D. W. Gow, Neuropsychology Laboratory, VBK 821, Massachusetts General Hospital, 55 Fruit Street, Boston, MA 02114 (e-mail: gow @ helix.mgh.harvard.edu). vowel harmony, complex infixation effects, and assimilation appear to demonstrate complex nonlinear mappings between features and segments (see Kenstowicz, 1994, for a review). For example, in English place assimilation, coronal segments appear to take the place of articulation of a subsequent noncoronal. The coronal $/ \mathrm{n} /$ in cone seems to take the labial place of the $[\mathrm{b}]$ in the phrase cone bent and may end up sounding like the labial [m]. According to the autosegmental model, the labial feature that is initially associated only with the $[\mathrm{m}]$ forms a second association with the $/ \mathrm{n} /$. This ultimately leaves the labial feature with links to two segments, as is shown in Figure 1.

Several researchers have suggested that an analogous mechanism relates feature cues recovered from the speech signal to segmental positions in lexical representations. Lahiri and Marslen-Wilson (1991) found that Englishspeaking listeners expect a nasal segment to follow a nasalized vowel in gated speech. In their analysis, listeners employ underspecified phonological representations to recognize words in which noncontrastive feature values (e.g., vowel nasality in English) are not represented in the lexicon. They may detect evidence of nasality during a vowel, but they cannot assign it to the vowel, because it is an unspecified feature. Unable to associate the feature with the vowel, listeners are forced to associate it with another segment. Lahiri and Marslen-Wilson suggested that association can take place over a three-segment window centered on the segment during which a feature cue is detected. The notion that listeners rely on underspecified representations to tolerate lawful phonological variation while maintaining strict matching criteria for invariant phonological categories is undermined by the finding that listeners discriminate between lexical candidates (e.g., cone and comb) in contrasts that rest on a putatively un- 


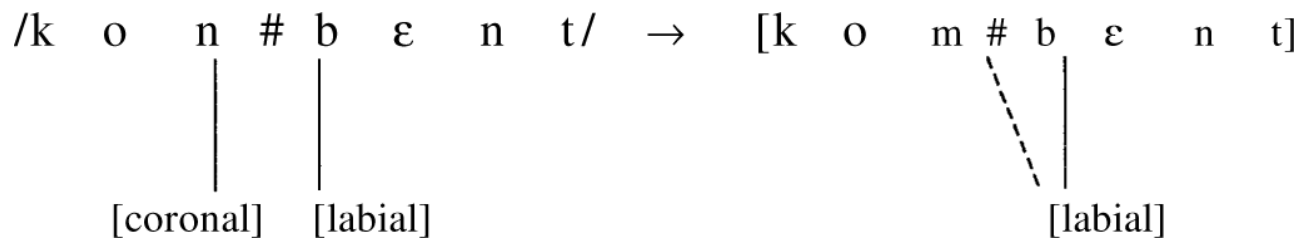
Figure 1. Autosegmental representation of place assimilation as feature spreading in the phrase cone
bent.

specified feature value, such as coronal place in English (Gaskell \& Marslen-Wilson, 2001; Gow, 2002). However, the idea that assimilation distorts the mapping between recovered features and segments and that listeners resolve the resultant ambiguity by determining the proper mapping may still be viable. Gow (2001) applied the same notion, that assimilation distorts the mapping between features and segments and that listeners are able to recover the appropriate mapping, to account for the facilitated identification of the context that follows place-assimilated underlying coronals in a phoneme-monitoring task. This mechanism could also account for widespread evidence that anticipatory coarticulation improves speech perception (Kuehn \& Moll, 1972; LaRiviere, Winitz, \& Herriman, 1975; Lehiste \& Shockey, 1972; Mann \& Repp, 1981; Martin \& Bunnell, 1981; Ostreicher \& Sharf, 1976; YeniKomshian \& Soli, 1981). Although the notion of nonlinear association between features and segments was originally intended to account for representational phenomena, it seems to provide a reasonable framework for explaining processing effects as well.

A similar parsing problem exists at the level of feature identification. Most contrastive features are encoded by multiple feature cues (Bailey \& Summerfield, 1980). For example, voicing distinctions are encoded in voice onset time and the duration of the vowel immediately preceding a consonant. The place of articulation of stop consonants is encoded in formant values surrounding the interval of consonant closure, as well as in the spectrum of the burst associated with the release of the consonant. Each of these cues occurs at a different time in the speech stream. When listeners recognize speech, the interpretation of one feature cue appears to be modulated by the value of other cues to that feature (Best, Morrongiello, \& Robson, 1981; Hodgson \& Miller, 1996; Parker, Diehl, \& Kluender, 1986; Repp, 1982; Sinnott \& Saporita, 2000; Summerfield \& Haggard, 1977; Treisman, 1999). The existence of such trading relationships suggests that the listener integrates temporally dispersed cues to the same feature. It follows, then, that listeners have a mechanism for determining which feature cues are associated with the same segment.

The mechanism for associating cues with each other to recognize segments could work in several ways. One possibility is that listeners infer the mapping between recovered features and abstract segments on the basis of implicit knowledge of phonological systems when nonlinear mappings are the result of lawful phonological processes, such as place assimilation. Gaskell and Marslen-Wilson $(1996,1998)$ suggested that listeners invert phonological rules to infer whether a form may be the result of assimilation in a given context. This inference could reflect implicit knowledge of the phonological rules that give rise to assimilation or of the statistical regularities in the mapping between the acoustic form of assimilated segments produced by these rules and abstract representations of phonemic sequences.

Another possibility is that feature parsing reflects perceptual grouping mechanisms operating at the level of feature cues. The distribution of feature cues for adjacent segments over time and evidence for the integration of multiple feature cues suggest that listeners group feature cues. Research in auditory and visual perception suggests that elements are grouped on the basis of a variety of factors, including schemata reflecting higher orders of organization, temporal or spatial proximity, and the similarity of preattentive features (see Boardman, Grossberg, Myers, \& Cohen, 1999; Bregman, 1990; Julesz \& Hirsh, 1972; Wertheimer, 1923/1938). Evidence from studies in which stimuli are constructed that draw these organizational principles into opposition has demonstrated that these grouping principles may act like gravitational fields, exerting competing attractions for an element to participate in one or another grouping (Bregman, 1978; Bregman \& Rudnicky, 1975; McNally \& Handel, 1977). In the domain of feature parsing, proximal cues to the same feature value may be pulled together on the basis of their similarity. Adjacent segments (representing higher order levels of organization) or neighboring cues to a common feature value may also compete to attract feature cues into one or another grouping.

\section{English Place Assimilation}

Assimilation provides a useful set of phenomena for examining feature parsing. As has been noted above, autosegmental phonology treats assimilation as a featurespreading process in which one feature is associated with more than one segment. This description is consistent with Lahiri and Marslen-Wilson's (1991) evidence that Englishspeaking listeners associate assimilated nasality encountered in vowels with subsequent nasal consonants. This suggests that listeners recover the linking that leads nasality to spread to vowels in the first place. Articulatory and acoustic evidence suggests that assimilation may pose an even more complicated feature-parsing problem, given the information encoded in the physical realization of assimilated segments. 
Although there is some debate over whether natural assimilation ever creates complete or categorical change in acoustic feature cues (Gow, 2003; Nolan, Holst, \& Kuhnert, 1999), all existing articulatory and acoustic evidence shows that this process often leads to gradient modification of place of articulation (Barry, 1985; Gow, 2001, 2002, 2003; Holst \& Nolan, 1995; Jun, 1996; Kerswill, 1985; Nolan et al., 1996). Articulatory descriptions of place assimilation focus on two factors. The first is gestural overlap. Stop consonants are produced by gestures that occlude the vocal tract. When a speaker produces a coronal stop, the tongue tip is moved forward and makes a closure at the alveolar ridge. Labial stops are made by forming a constriction at the lips, and velar stops are made by raising the tongue body to form a constriction with the soft palate. Electropalatographic (Barry, 1985; Browman \& Goldstein, 1990; Kerswill, 1985) and aerodynamic (Silverman \& Jun, 1994) evidence suggests that the gestures that form these closures overlap in time. In the case of stop consonants, superimposing two gestures has an interesting acoustic result. Although two gestures are made, airflow through the vocal tract becomes blocked at only one point in time. Thus, the two gestures appear to be fused into one acoustic landmark, consistent with the production of just one segment. Jun (1996) has argued that overlap alone is insufficient to create perceived assimilation. Jun found that assimilation also requires reduction of the assimilated segment. For example, a speaker producing the phrase cone bent may initiate the /b/ closure in bent while forming the $/ \mathrm{n} /$ closure in cone. Unlike normal stop closure gestures, the assimilated /n/ gesture tends to be incomplete. Electropalatographic data show that there is incomplete contact with the alveolar ridge in many cases and no contact in up to half of all instances of assimilation in read speech produced at a normal rate (Barry, 1985; Kerswill, 1985).

The acoustic consequences of gestural overlap and reduction define the computational problem that assimilation poses for the listener. Gow (2003) found that, across speakers, coronal segments that have undergone spontaneous labial assimilation have distinctive acoustic characteristics that are intermediate between those of labial and coronal segments. This raises the question of what place information listeners actually abstract from the speech signal. Gow (2002) has shown that listeners differentiate between strongly assimilated tokens of right that resemble ripe and unmodified tokens of ripe produced in the same contexts. The fact that listeners can distinguish between right berries and ripe berries suggests that they recover the underlying coronality of the assimilated segment on the basis, at least in part, of bottom-up information in the speech signal.

There is also evidence that listeners recover information about the following segment from assimilated segments. Evidence from gating (Lahiri \& Marslen-Wilson, 1991), phoneme monitoring, and rhyme priming (Gow, 2001) suggests that the processing of postassimilation context is enhanced by assimilation. Once again, these ef- fects appear to derive from the acoustic form of assimilated segments. Gow (2001) found that listeners show facilitated monitoring for segments occurring immediately after spontaneously assimilated segments. In a similar study, Gaskell and Marslen-Wilson (1998) found no such facilitation for targets immediately following pseudoassimilated segments created by speakers deliberately pronouncing a coronal segment as a noncoronal. The distinction between spontaneous assimilation, which presumably reflects overlapping articulatory gestures and the partial reduction of the modified gesture, and deliberate pseudoassimilation, which does not, suggests that this processing advantage depends on the acoustic consequences of overlap in spontaneous assimilation.

Together, the results of these studies suggest that spontaneous gradient assimilation may produce segments that preserve underlying contrasts and enhance the processing of assimilation context segments. In effect, assimilated segments appear to encode two places of articulation. In order to use all of this information, listeners have to determine which feature information reflects underlying form and which reflects the assimilated features of another segment. To determine whether this is the featureparsing problem presented by assimilation, it is necessary to establish whether assimilated segments truly encode two places of information.

There is no direct evidence that the same assimilated token both preserves underlying place information and provides information about the place of the subsequent segment. Acoustic or articulatory data showing that assimilated segments may combine elements of two places of articulation are only suggestive, because it is unclear how listeners use this information. Existing behavioral evidence is similarly incomplete. Gow (2001) used many of the same stimulus tokens to demonstrate enhanced context processing and the recovery of underlying form in separate experiments, but the items used in these studies were words, like green, that approximated nonwords (e.g., greem) when assimilated. It is possible that priming in this study may reflect the best fit between a nonword prime (greem) and a real word (green). It may also be the result of incomplete processing of the prime item. In this study, lexical decision probes were presented immediately at the offset of the prime. It is possible that this design allowed insufficient rise time for phonetic processing prior to the lexical decision and, so, lexical activation reflected the onset of the prime, which matched the probe, but not the offset of the prime, which did not. In either event, it appears that listeners could have accessed the underlying form of the modified word without actually recovering the underlying form of the modified segment from the speech signal. Therefore, these results do not necessarily demonstrate that the same modified segment encodes the places of articulation of two segments. Similarly, the results of Gow (2002) demonstrated that assimilated segments show preserved evidence of underlying place, but they do not address the question of whether the same tokens provide information about the place of the subsequent segment. One 
possibility is that listeners recover the underlying place of these particular tokens because there is too little reduction or gestural overlap to obscure it.

\section{Goals}

The present research addressed two broad questions. The first was whether assimilated segments can simultaneously encode recoverable information about the underlying form of both the assimilated segment and the segment that follows. The only way to establish this claim is to show that one group of assimilated speech stimuli can be used to demonstrate both the preserved identification of underlying form and the facilitated perception of postassimilation context. Experiments 1 and 2 employed different methodologies, using the same stimuli, to this end. In Experiment 1, form priming was employed to determine whether listeners recover the underlying form of a set of place-assimilated segments. In Experiment 2, the question of whether assimilation enhances the perception of postassimilation context was examined. If assimilated segments encode recoverable place information for two segments, subjects should selectively show priming for the underlying form of the probe item in Experiment 1 and should show facilitated monitoring for labial targets following the same labialized segments in Experiment 2.

The second question is how do listeners resolve feature parsing posed by assimilated speech. Experiment 3 was performed to examine whether these context effects reflect listeners' implicit knowledge of the regular modifications produced by lawful assimilation or more fundamental perceptual mechanisms.

\section{EXPERIMENT 1}

The purpose of Experiment 1 was to determine whether the assimilated speech tokens that serve as stimuli in the three experiments presented here encode recoverable evidence of their underlying places of articulation. This experiment also extended two experiments by Gow (2002) that demonstrated that listeners selectively access the underlying form of strongly assimilated items that bear a strong resemblance to competitors.

\section{Method}

Subjects. Forty-two adults drawn from the Massachusetts Institute of Technology community, including 18 men and 24 women with a mean age of 23.6 years, served as subjects. All were native speakers of English, with self-reported normal hearing and (corrected) vision. The subjects were paid for completing the experiment and received a performance bonus if they met criteria for overall speed and accuracy on the lexical decision task and for accuracy on a memory test administered after the experiment.

Stimuli. Forty-eight familiar monosyllabic words ending in coronal segments were selected as prime items. Each of these words could be transformed into another familiar word by making the final coronal segment a labial. For example, the word cone ends in the coronal segment $/ \mathrm{n} /$ and can be transformed into the word comb by changing only the place of articulation of that segment. These items were embedded in sentential contexts in which the following word was a monosyllable beginning with a labial. In this context, assimi- lation caused the underlying coronal prime to perceptually approximate its labial-final lexical neighbor. For example, the word cone might sound very much like the word comb in the phrase cone bent. Care was taken to ensure that both readings of the prime were syntactically and semantically viable in their sentential contexts. For the purposes of subsequent experiments, the words immediately following the assimilated item began with $/ \mathrm{b} /$ and $/ \mathrm{p} /$ in an equal number of cases. These labial segments served as targets in the monitoring task in Experiment 2. The experimental sentences used in Experiment 1 are provided in Appendix A. In addition to these sentences, 208 filler sentences were constructed.

These sentences were read aloud by an experimentally naive adult male speaker who had been instructed to read them in a fluent, casual, and somewhat rapid fashion. The speaker read each sentence at least four times. All the sentence tokens were recorded in a soundattenuating chamber, using a digital tape recorder sampling at $44.1 \mathrm{kHz}$ and a professional quality microphone. These tokens were transferred to a computer, where they were volume-equalized and edited for use in the three experiments. Two listeners heard each of the sentences and jointly selected the token of each sentence that they judged to show the most pronounced assimilation. Only these strongly assimilated tokens were included in subsequent acoustic analyses and experiments.

Acoustic analyses were performed to determine whether the assimilated tokens that served as stimuli in the present experiments showed typical characteristics of assimilation and to ensure that these tokens reflected partial assimilation, rather than a combination of nonmodification and discrete modification. For purposes of comparison, two additional versions of the experimental sentences were recorded. One version replaced the labial context following assimilated segments with a coronal one. For example, the phrase cone bend was replaced with the phrase cone dents in the speaker's script. This manipulation produced tokens of cone in which the final segment was an unmodified coronal. In a third version of the script, the coronal $/ \mathrm{n} /$ in the phrase cone bend was replaced with the labial $/ \mathrm{m} /$ to produce the phrase comb bend. Acoustic analyses of these three versions allowed for comparison between minimal triplets ending in unmodified coronals, underlying labials, and labial-assimilated underlying coronals. The additional tokens were also used in several conditions in Experiments 2 and 3. The frequencies $(F 1, F 2$, and $F 3)$ and amplitudes $(A 1, A 2$, and $A 3)$ of the first three formants were measured in the penultimate pitch periods before the closure of the critical segment. The results of these measurements are summarized in Table 1. Formant frequency values showed the same pattern as that found in other studies of spontaneously assimilated coronal stops (Gow, 2001, 2002, 2003; Gow \& Hussami, 1999). The mean frequency of each of the first three formants of assimilated segments was intermediate between those of unmodified coronals and labials. The observed pattern of formant amplitudes was also consistent with those found in previous studies, with assimilated tokens consistently showing lower values of $A 1, A 2$, and $A 3$ than those found in unmodified segments. Together, these measures suggest that the assimilated tokens studied here reflect the general characteristics of spontaneously assimilated segments produced by other speakers.

For the purposes of the present research, it was important to establish that the stimuli represent the middle of the assimilation continuum, rather than its extremes. This is a particularly important concern in the case of measures of formant frequency, where the intermediate mean values shown by assimilated segments could potentially be an artifact of averaging, rather than a true indication of central tendency. To test this hypothesis, acoustic measures of assimilated tokens were submitted to the Kolmogorov-Smirnov test of normality. These tests failed to show significantly nonnormal or multimodal distributions for $F 1, F 2, A 1, A 2$, or $A 3$ ( $p>.05$ ). One of the measures, $F 3$, did show a nonnormal distribution (Kolmogorov-Smirnov $Z=1.5, p<.05)$. Inspection of the data revealed evidence of a bimodal distribution, with a minor second prominence associated with 
Table 1

Acoustic Comparisons at the Penultimate Pitch Period before Consonantal

Closure Between Unmodified Coronal, Labial-Assimilated Coronal, and

Underlyingly Labial Segments in Experimental Stimuli From Experiments 1-3

\begin{tabular}{|c|c|c|c|}
\hline Measure & $\begin{array}{l}\text { Unmodified } \\
\text { Coronal } \\
([\text { kon }])\end{array}$ & $\begin{array}{c}\text { Labial-Assimilated } \\
\text { Coronal } \\
\left(\left[\mathrm{ko}_{\mathrm{m}}^{\mathrm{n}}\right]\right)\end{array}$ & $\begin{array}{c}\text { Underlyingly } \\
\text { Labial } \\
([\mathrm{kom}])\end{array}$ \\
\hline \multicolumn{4}{|c|}{ Formant Frequency $(\mathrm{Hz})$} \\
\hline$F 1$ & 476.1 & 480.1 & 494.5 \\
\hline$F 2$ & 1635.4 & 1533.1 & 1476.7 \\
\hline$F 3$ & 2532.1 & 2401.5 & 2341.9 \\
\hline \multicolumn{4}{|c|}{ Formant Amplitude (dB) } \\
\hline$A 1$ & 34.2 & 29.9 & 33.5 \\
\hline$A 2$ & 37.6 & 28.9 & 30.5 \\
\hline$A 3$ & 27.9 & 24.8 & 25.1 \\
\hline
\end{tabular}

seven tokens with high $F 3$ values. Significantly, tokens in the unmodified labial condition showed the same pattern. In both cases, the outliers were the seven items with the high front vowel /i/ immediately preceding the target. This is consistent with the observation that this vowel typically has a much higher $F 3$ than do other vowels (Petersen \& Barney, 1952). When these items were removed from the sample, $F 3$ showed an overall normal unimodal distribution, as was confirmed by the Kolmogorov-Smirnov test $(Z=0.8, p>$ .05 ), suggesting that evidence of a bimodal distribution of $F 3$ values was an artifact of the preclosure vowels used in a subset of stimuli.

The lexical decision stimuli were all monosyllabic items presented on screen in uppercase 18-point Helvetica font. Half were familiar words, and half were pronounceable nonwords. All of the 48 experimental trials employed primes that were real words. Related primes were items that corresponded to the underlying or apparent surface forms of their accompanying primes. For example, if the prime word was a token of the word cone that underwent labial assimilation to resemble $\operatorname{comb}$, the related primes were CONE and Сомв. Probes that served as related items in some trials were paired with different primes in other trials to form the unrelated condition. Thus, if CONE and COMB served as related probes following cone, they might also serve as unrelated probes when presented after mat. Probes corresponding to the underlying coronal forms of primes had a mean frequency of 52.1 occurrences, and probes corresponding to their surface labial-final forms had one of 21.8 occurrences, in Francis and Kučera's (1982) database. In filler trials, probes were selected that bore no semantic or significant phonological relationship with words in the accompanying acoustic prime sentence.

Procedure. The subjects were tested individually in a soundattenuating chamber. They completed the task while wearing professional quality headphones and seated in front of a 17-in. computer monitor with a button box mounted on a table in front of them. At the beginning of the experiment, instructions were presented visually on the computer monitor. After giving the subjects time to read the instructions, the experimenter repeated them orally. The subjects were instructed to listen carefully to all the sentences in preparation for a memory test to be given at the end of the testing session. The purpose of this task was to compel the subjects to attend to the auditory stimuli. They were also told that they would see an item on the computer screen at some point during each sentence and that it was their task to determine whether the item was a real word or a made-up word. With their dominant hand resting over the button box at all times, they were to press one key if the item was a real word and the other if it was a nonword. They were instructed to make their responses as quickly and accurately as possible and that they would receive a monetary bonus if they met certain criteria for their overall speed and accuracy on the buttonpress task and for accuracy on the memory task. Trial order was randomized. Stimuli were presented and responses were recorded using Psyscope software (Cohen, MacWhinney, Flatt, \& Provost, 1993). The lexical decision probe appeared for $500 \mathrm{msec}$ during each trial. If the subjects did not respond to a probe within $1,400 \mathrm{msec}$, they heard a 100 -msec warning tone. Auditory stimulus presentation was not disrupted by the presentation of visual probes. There was a 1-sec intertrial interval between the subject's response and the onset of the next sentence. Experimental testing began with 10 practice trials in order to familiarize the subjects with the task and establish a consistent response baseline. In experimental trials, lexical decision stimuli were presented $100 \mathrm{msec}$ after the offset of the assimilated prime word to allow the subjects to complete phonetic processing of the entire prime before beginning the probe task. After completing all of the experimental trials, the subjects completed a five-item forced-choice recognition task in which they were presented with two words and were asked to choose the one that completed an incomplete sentence fragment taken from the filler trials.

Design. There were four experimental conditions created by crossing two levels of prime-probe relatedness (related vs. unrelated) with two levels of probe type (coronal final vs. labial final) in a between-subjects design. Four different versions of the experiment were constructed. Each contained the same prime and probe items, but in different combinations. The four versions included 12 trials in each of the four conditions, and all prime items were presented once in each of the conditions across trials. Trial order was randomized between subjects.

\section{Results and Discussion}

In order to minimize the impact of anticipatory and strategic responding, monitoring latencies less than $200 \mathrm{msec}$ or greater than 1,200 msec were eliminated from all analyses. In addition, 2 subjects were excluded from the final analyses for showing overall accuracy rates below $85 \%$ or mean reaction times greater than $1,000 \mathrm{msec}$ on the lexical decision task. The results of these analyses are summarized in Table 2.

All data were analyzed using preplanned contrast analyses exclusively, because this technique allowed the most specific and direct test of whether priming occurred (Rosenthal \& Rosnow, 1985). The subjects showed a 24msec priming effect in lexical decision reaction time for the underlying forms $\left[t_{1}(39)=1.9, p<.05 ; t_{2}(47)=2.1\right.$, $p<.05$ ] but did not show significant priming for the apparent surface forms of the prime items $\left[t_{1}(39)=1.2, p>\right.$ $\left..05 ; t_{2}(47)=1.2, p>.05\right]$. Thus, the subjects hearing to- 
Table 2

Mean Reaction Times (RTs, in Milliseconds) and Accuracy Rates

(\% Correct) for Lexical Decisions in Experiment 1

(With Mean Standard Errors)

\begin{tabular}{|c|c|c|c|c|c|}
\hline \multirow[b]{2}{*}{ Probe Type } & \multicolumn{2}{|c|}{$\begin{array}{c}\text { Related } \\
\text { Prime } \\
\left(\left[\mathrm{ko}_{\mathrm{m}}^{\mathrm{n}}\right]\right)\end{array}$} & \multicolumn{2}{|c|}{$\begin{array}{c}\text { Unrelated } \\
\text { Prime } \\
\left(\left[\mathrm{m}_{\mathrm{p}}^{\mathrm{t}}\right]\right) \\
\end{array}$} & \multirow{2}{*}{$\begin{array}{r}\text { Priming } \\
\text { Effect }\end{array}$} \\
\hline & $M$ & $S E$ & $M$ & $S E$ & \\
\hline \multicolumn{6}{|c|}{ Noncoronal (e.g., сомB) } \\
\hline RT & 641 & 6.85 & 654 & 6.88 & 13 \\
\hline Accuracy rate & 92 & 1.20 & 90 & 1.34 & 2 \\
\hline \multicolumn{6}{|c|}{ Coronal (e.g., CONE) } \\
\hline RT & 625 & 7.23 & 649 & 7.24 & 24 \\
\hline Accuracy rate & 89 & 1.20 & 90 & 1.32 & 1 \\
\hline
\end{tabular}

kens of cone that resembled the word comb showed priming for CONE, but not for COMB. An analysis of accuracy data revealed no significant effects. This is consistent with a number of results indicating that listeners show priming for the underlying form of assimilated segments (Coenen, Zwitserlood, \& Bölte, 2001; Gaskell \& Marslen-Wilson, 1996; Gow, 2001, 2002). No significant correlation was found between differences in priming magnitude and lexical decision target word frequency $(r=.42, p>.05)$, suggesting that the observed pattern of priming cannot be attributed to a frequency bias in lexical activation.

The central question in the interpretation of these stimuli is whether listener performance on the task reflects perceptual analysis of the speech signal or top-down inferential processes. Given evidence from the acoustic analyses that assimilated segments physically differed from labials, the simplest interpretation is that the listeners were able to perceptually discriminate between assimilated segments and labials. If this is the case, it would appear that the assimilated tokens employed in this experiment encoded recoverable information about their underlying coronal place of articulation.

Gaskell and Marslen-Wilson (1996, 1998, 2001) have provided a potential account for the results of Experiment 1 that does not rely on the acoustic encoding of underlying coronal place. They suggested that listeners hearing completely or discretely assimilated segments infer underlying place on the basis of implicit phonological knowledge. For example, a listener hearing [kom] bent might infer that the labial place of the final segment in [kom] is assimilated from the initial labial in bent. Since only coronals can assimilate labial place in English, the listener could infer that the underlying segment was the coronal $/ \mathrm{n} /$ in cone. Such an analysis of the present results is not empirically supported. First, there is no evidence that listeners rely on this type of inference in the absence of strong semantically biasing contexts favoring the coronal interpretation of the assimilated segment. Gaskell and Marslen-Wilson (2001) found that listeners reliably access only the item corresponding to the surface form of potentially assimilated primes in contexts conducive to assimilation and, in fact, show a statistically nonsignificant trend toward inhibiting the potentially underlying forms of such items unless semantically biasing contexts are present. Similarly, Gow (2002) found that listeners hearing tokens of potentially assimilated items, such as ripe berries, access only their surface forms, whereas listeners hearing spontaneously assimilated tokens of right berries access only their underlying forms. Phonological inference may play a role in the processing of assimilated speech, but this role appears to be limited to cases in which lexical or semantic factors mitigate against accepting the surface form of an item. Given the use of semantically neutral contexts and the fact that both coronal and labial interpretations of the critical stimuli are lexically viable, it appears that listeners accessed the underlying form of assimilated items in Experiment 1 on the basis of bottom-up acoustic evidence, rather than on the basis of top-down application of phonological inference.

\section{EXPERIMENT 2}

In Experiment 2, a phoneme-monitoring task was employed to determine whether the assimilated stimuli employed as primes in Experiment 1 encode usable acoustic evidence of the identity of subsequent context. If they do, it is predicted that monitoring latencies for postassimilation segments should be shorter than latencies associated with detecting the same phonemes when they follow nonassimilated contexts. It is further hypothesized that if this effect depends on the specific acoustic consequences of partial assimilation, listeners will show facilitated phoneme monitoring after partially assimilated tokens, such as the labialized token of cone $\left(\left[\mathrm{ko}_{\mathrm{m}}^{\mathrm{n}}\right]\right)$, but not after tokens of minimally contrasting words that end in an underlying labial (e.g., comb, [kom]). Evidence that listeners recognized the underlying place of assimilated segments in Experiment 1 and showed facilitated detection of the place of a subsequent segment in Experiment 2 would support the claim that the specific assimilated segments used in these experiments encode usable information about different places of articulation for two segments.

\section{Method}

Subjects. The subjects were 11 men and 19 women, with a mean age of 24.3 years, drawn from the Massachusetts Institute of Tech- 
Table 3

Examples of Base Sentence Types Used to Create

Phoneme-Monitoring Stimuli in Experiment 2

Unmodified coronal: The plastic cone dents easily. ([kon])

Labial assimilated: The plastic cone bent easily. ([ $\left.\left[\mathrm{ko}_{\mathrm{m}}^{\mathrm{n}}\right]\right)$

Unmodified labial: The plastic comb bent easily. ([kom])

Note-Phonetic transcriptions of the surface forms of critical items are shown in parentheses.

nology community. All met the same inclusion criteria as those used in Experiment 1 and were paid for participating in the experiment.

Stimuli. The stimuli were derived from the 48 sentences with partially assimilated items, employed as primes in Experiment 1, and from the additional sentences recorded for the acoustic analyses used to characterize their physical resemblance to minimally contrasting unmodified labial and coronal segments. The three sentence types are illustrated in Table 3. In assimilation and labial contexts, the context word began with the target phonemes $/ b /$ in half of all the tokens and $/ \mathrm{p} /$ in the other half. In addition to these tokens, the same 208 filler sentences as those in Experiment 1 were used in this experiment. One hundred and seventy-four of these sentences contained one instance of a target phoneme in a word-initial position, and 34 contained no instances of a target phoneme. The position of the target phoneme within sentences was evenly distributed across items, to prevent the subjects from forming strong expectations about the position of target phonemes.

The final stimuli used in the experiment were created by crosssplicing between the three base sentence types. Each of the base sentences was gated at the last zero-crossing immediately before the release of the segment following the critical coronal, labial, or assimilated item. For example, a sentence including the phrase comb bent would be gated just prior to the release of the $/ \mathrm{b} /$ in bent . In all cases, the final stop in the critical token was unreleased, as is commonly the case in connected speech. For each triplet, the end of a fourth sentence was cross-spliced onto these three gated sentence contexts to form complete sentences. In half of these cases, the fourth sentence was a previously unused token of the labial version of the sentence, and in the other half it was a previously unused token of an assimilated version of the sentence. All cross-splices were made in the same easily located steady-state portion of the waveform, to avoid the creation of acoustic splicing artifacts. Two listeners evaluated all cross-splices to ensure that the stimuli were natural sounding and showed no discernable temporal, prosodic, or acoustic evidence of splicing. Stimuli judged to show such discontinuities were replaced with new stimuli created by cross-splicing a different token of the sentence offset onto the same three sentence onsets. Splicing in this manner meant that the same physical token of the target phoneme was used in all three sentence conditions. The experimental sentences used in Experiment 2 are provided in Appendix B.

Procedure. The subjects were tested individually in a soundattenuating chamber, using the same physical set-up as that employed in Experiment 1. Instructions were presented visually on a computer monitor. The task was also explained verbally by an experimenter prior to testing. The subjects were instructed to listen carefully to each sentence and to press a reaction key with the index finger of their dominant hand as soon as they heard the target segment in each sentence. They were also told that some items would not contain the target and that they should press another key at the offset of the sentence to indicate that the target had not appeared. They were also informed that they would take a short memory test at the end of the experiment, to demonstrate that they had listened carefully to each sentence, and that they could earn a small monetary bonus for doing well on the test and responding quickly during the experiment. The subjects sat at a desk and listened to auditory stimuli through high-quality headphones. Psyscope stimulus presen- tation software (Cohen et al., 1993) was used to randomize and present stimuli and to collect data, and the Psyscope button box served as the response input device. If the subjects took more than $1,400 \mathrm{msec}$ to respond to a target, they were played a warning tone. There was a 1-sec interval between the subject's response or the offset of the warning tone and the beginning of the next trial. Testing was broken down into three blocks. In the initial practice block, the subjects monitored for the target / $\mathrm{d} /$ in eight sentences. This practice block let the listeners familiarize themselves with the task and allowed performance to stabilize. No experimental items appeared in the practice block. In the first experimental block, the subjects monitored for $/ \mathrm{b} /$, and in the second block they monitored for $/ \mathrm{p} /$. The subjects were given a self-regulated rest period between blocks. At the end of testing, the subjects completed a short memory task consisting of five items, in which they were to choose between two words to complete a sentence that appeared in the on-line portion of testing.

Design. There were three primary experimental conditions, corresponding to the three forms of the items that immediately preceded the target phoneme. In the first condition, this item was a token of a word ending in a coronal segment that had undergone labial assimilation (e.g., $\left.\left[\mathrm{ko}_{\mathrm{m}}^{\mathrm{n}}\right]\right)$. In the second condition, this item was unmodified [kon], and in the third condition this item was the word ending in an underlying labial [kom]. The experiment employed a betweensubjects design, with each subject contributing an equal number of responses in all conditions and each item appearing in only one condition per subject. There were 8 trials in the practice block and 124 trials in each of the two experimental blocks. Target phonemes appeared in all but $12.5 \%$ of the trials across the three blocks, with target position within each sentence randomized to make it unpredictable. Trial order was randomized within each block, with a new randomization applied for each subject.

\section{Results and Discussion}

Table 4 shows the mean monitoring latencies for targets following assimilated coronals, unmodified labials, and unmodified coronals. Analyses were completed using the same exclusion criteria and data preparation techniques as those used in Experiment 1. There was a significant main effect for target context $\left[F_{1}(2,29)=8.1, p<.001 ; F_{2}(2,47)=\right.$ $7.3, p<.001$ ], with mean monitoring latencies of $562 \mathrm{msec}$ in assimilated coronal contexts, $619 \mathrm{msec}$ in unmodified coronal contexts, and $603 \mathrm{msec}$ in unmodified labial contexts. The nature of this effect was further explored in a series of planned contrast analyses comparing the pattern of differences between the three conditions.

Targets following assimilated coronals were detected more quickly than targets following unmodified coronals $\left[t_{1}(29)=11.2, p<.001 ; t_{2}(47)=3.8, p<.001\right]$ and unmodified labials $\left[t_{1}(29)=1.8, p<.05 ; t_{2}(47)=2.1, p<\right.$ $.05]$. However, there was no significant difference between monitoring latencies for labial targets following unmodified labial contexts (e.g., [m] in comb), as compared with unmodified coronal contexts [e.g., [n] in cone; $\left.t_{1}(29)=1.0, p>.05 ; t_{2}(47)=0.9, p>.05\right]$.

The processing advantage shown for targets in assimilated contexts replicates the results of Gow (2001) and is consistent with independent evidence for contextual facilitation following assimilation from studies employing gating (Lahiri \& Marslen-Wilson, 1991) and rhyme priming (Gow, 2001). It is also generally consistent with a wide body of evidence showing that coarticulation facilitates the pro- 
Table 4

Mean Monitoring Latencies (in Milliseconds) for Word-Initial Stop Consonants in Experiment 2

\begin{tabular}{|c|c|c|c|}
\hline \multirow[b]{2}{*}{ Context } & \multirow[b]{2}{*}{ Example } & \multicolumn{2}{|c|}{ Reaction Time } \\
\hline & & $M$ & $S E$ \\
\hline Labial assimilated & $\ldots$ cone bent $\ldots \rightarrow\left[\mathrm{ko}_{\mathrm{m}}^{\mathrm{n}}\right.$ bent $]$ & 562 & 12.01 \\
\hline Unmodified coronal & $\ldots$ cone bent $\ldots \rightarrow$ [kon bent $]$ & 619 & 13.25 \\
\hline Unmodified labial & $\ldots$ comb bent $\ldots \rightarrow$ [kom bent $]$ & 603 & 11.97 \\
\hline
\end{tabular}

Note-The underlined phoneme is the target in each example.

cessing of subsequent context (Kuehn \& Moll, 1972; LaRiviere, Winitz, \& Herriman, 1975; Lehiste \& Shockey, 1972; Mann \& Repp, 1981; Martin \& Bunnell, 1981; Ostreicher \& Sharf, 1976; Yeni-Komshian \& Soli, 1981).

The fact that labialized coronal contexts facilitated monitoring whereas unmodified labial contexts did not suggests that facilitation relies on the unique acoustic properties of partially assimilated segments. This result is consistent with the finding by Gaskell and MarslenWilson (1998) that listeners show no facilitation for targets following pseudoassimilated items, such as the word freight deliberately pronounced [freip] before a labial.

The effect of the acoustic properties of context segments on monitoring latency could be interpreted in several ways. One explanation is that the cross-splicing manipulation is more disruptive and prone to subtle acoustic discontinuity in the labial and coronal conditions than in the assimilation condition. There are several problems with this interpretation. The first is that the transitions that occur in each of the three conditions all occur in natural speech. Place assimilation is an optional process, and so listeners may regularly hear unmodified coronals followed by labials. Furthermore, half of the target tokens were produced in contexts in which the preceding segment was an underlying labial. The deeper argument against this interpretation turns on evidence from a rhyme-priming study by Gow (2001), which showed that this context effect turns on the perceived or anticipated identity of the postassimilation segment. Gow (2001) showed that assimilation plays a role in determining which segment a listener anticipates, rather than simply affecting how efficiently postassimilation contexts are identified. Such a result cannot be attributed purely to the potential unnaturalness of cross-spliced stimuli. The more likely interpretation of this result is that listeners recover acoustic evidence of the place of articulation of the postassimilation segment during the course of the assimilated segment. This view would explain the Gow (2001) rhyme-priming result and is consistent with the observation that assimilated segments appear to reflect the combination of two overlapping gestures and show acoustic characteristics intermediate between those of the underlying and the assimilating segments.

In summary, the results of Experiment 2 support the hypotheses that assimilation facilitates the detection of subsequent context and that this facilitation is related to the acoustic realization of partially assimilated segments. When considered in combination with the results of Experi- ment 1, they further suggest that assimilated segments encode evidence for the places of articulation of two adjacent segments.

The combined results of Experiments 1 and 2 support a characterization of partially assimilated segments that helps frame the mapping problem posed by assimilated speech. The results of the first experiment support the claim that recoverable information about the underlying place of articulation of segments is preserved in assimilation. The results of the second experiment suggest that recoverable information about the place of articulation of the subsequent segment is also encoded in the same tokens of assimilated segments. This means that listeners are faced with the problem of mapping one set of feature cues to two adjacent segments. This statement of the problem is consistent with articulatory analyses showing that two gestures are superimposed in assimilation. The implication of this characterization is that listeners' ability to recover the underlying place of assimilated segments is as much the result of a mapping process as the facilitated recognition of postassimilation context is. That is, listeners hearing strongly labialized tokens of the $/ \mathrm{n} /$ in cone bent recover evidence of both coronal and labial place from the closure after the first vowel and are able to recognize the speaker's intent to say cone, and not comb, because they successfully associate the recovered coronality with the [n] and the labiality with the subsequent [m]. The recognition of partially assimilated speech is, therefore, best viewed as a feature-parsing problem.

In Experiment 3, how listeners resolve this featureparsing problem was examined. Two classes of approaches should be considered. There is a knowledge-driven approach that relies on listeners' learned implicit understanding of regularities in the mapping between idealized surface forms in context and the underlying forms that give rise to them. This class would include network models that explicitly use statistical learning to model context effects in assimilation (Gaskell, Hare, \& Marslen-Wilson, 1995), and processing models such as the underspecification account (Lahiri \& Marslen-Wilson, 1991) and the phonological inference account (Gaskell \& Marslen-Wilson, $1996,1998,2001)$ that implicitly reflect knowledge of language-specific assimilation phenomena. Although specific models within this class, including phonological inference and underspecification, fail to account for existing results, as was noted earlier, the notion that language perception may reflect elements of statistical inference is consistent with a wide range of results (see Pitt \& McQueen, 1998; Saffran, Aslin, \& Newport, 1996).

The other approach favors general perceptual mechanisms to explain listeners' ability to cope with phonological modification. As I have already suggested, auditory grouping mechanisms could provide a perceptual account of the processing of assimilated speech within the featureparsing framework. Lotto and Kluender have provided an alternate perceptual account of the coarticulatory context effects that is couched in terms of auditory contrast phenomena (Holt, Lotto, \& Kluender, 2001; Lotto \& Kluen- 
der, 1998; Lotto, Kluender, \& Holt, 1997). Contrast effects are hypothesized to reflect a general processing mechanism by which small physical differences are perceptually exaggerated (Békésy, 1967; Hartline \& Ratcliff, 1957; Koffka, 1935; Warren, 1985). In one line of research, Lotto and Kluender (1998) demonstrated that nonlinguistic stimuli (sine-wave frequency modulated glides modeled on $F 3$ glide transitions) affect the perceived place of articulation of adjacent stop consonants. In another, Lotto et al. (1997) demonstrated that the Japanese quail (Coturnix coturnix japonica) shows evidence of compensation for coarticulation in the perception of stops following different types of glides. Critically, these demonstrations suggest that context effects can emerge without linguistic experience or a linguistic percept.

In Experiment 3, the subjects heard the same placeassimilated stimuli as those used in the two previous experiments. However, cross-splicing techniques were employed to replace the labial context that produced assimilation in the first place with a context showing coronal place. For example, the word bent with its labial onset induced labial assimilation of the $/ \mathrm{n} /$ in cone in the phrase cone bent. In the current example, bent was replaced with dents. Perceptual accounts predict that under these conditions, listeners should show priming for СОМB, but not for CONE. The perceptual grouping explanation predicts that the coronality of the $/ \mathrm{n} /$ in cone should group with the strong evidence of coronality associated with the /d/ in dents. In this way, evidence for coronality may be drawn away from the assimilated segment, leaving only evidence of labiality to associate with the last segment in the prime. If this takes place, listeners hearing the labialized final /n/ from cone bent in the new context (cone dents) should show priming for the labial-final СОМB, but not for the coronal-final CONE. An interpretation couched in terms of contrast effects would predict that listeners show priming for COMB when contrast with the coronal formant cues of the context segment pushes the perception of the assimilated formants into solidly labial perceptual space. Conversely, statistical models do not predict that listeners will access the labial alternative (COMB), because labial-tocoronal place assimilation does not occur in English and, so, listeners never encounter a mapping that would support this inference.

\section{EXPERIMENT 3}

Experiment 3 was a form-priming experiment that replicated Experiment 1, using modified tokens of the same assimilated stimuli in which the original labial postassimilation context was replaced with a coronal postassimilation context. The purpose of Experiment 3 was to test the predictions of statistical versus perceptual accounts of context effects in the processing of assimilated speech.

\section{Method}

Subjects. The subjects were 15 men and 23 women (mean age of 21.2 years) drawn from the same population and meeting the same eligibility criteria as the subjects in the previous two experiments. The subjects were reimbursed at the same rate and using the same incentive system as that used in Experiment 1. None of the subjects in the present experiment served in either of the earlier experiments.

Stimuli, Procedure, and Design. Experiment 3 closely replicated Experiment 1, using modified tokens of the original stimuli presented in combination with the same overall procedure and experimental design. The auditory stimuli were created by splicing new postassimilation contexts onto the original 48 experimental sentence tokens. The prime items in both Experiment 1 and the present experiment were monosyllabic words ending in coronal segments, such as cone, that formed minimal pairs with familiar words ending in labial segments, such as comb. In their original contexts, these words were followed by labial-initial words to induce labial assimilation. To create the stimuli for Experiment 3, each of these tokens was gated at a steady-state zero-crossing immediately prior to the release of the subsequent labial, and a new ending was spliced on. These new endings were created in the following way. Forty-eight additional sentences were constructed in which the same text through the critical word (e.g., cone) was followed by a new context beginning with a coronal segment. For example, the sentence The plastic cone bent easily was a base sentence that served as the auditory stimulus in Experiment 1, and a new sentence, The plastic cone dents easily, was recorded for the present experiment. Both tokens were recorded in a single session by the same speaker. The second sentence was gated in the same position, at the end of a steady-state zerocrossing just prior to the release of the segment following cone. As in the original sentences, the segment just prior to the edit was unreleased. The two gated sentence tokens were then digitally spliced together so that the token of The plastic cone//, ending in the labial assimilated $/ \mathrm{n} /$ that served as a prime in Experiment 1, was followed by the token of //dents easily from the new sentence. Two listeners verified that the edits created no discernable perceptual discontinuities or splicing artifacts. Cross-spliced tokens that showed such artifacts were replaced with new items formed by replacing the second half of the sentences with tokens that more closely matched the first

Table 5

Mean Reaction Times (RTs, in Milliseconds) and Accuracy Rates (\% Correct) for Lexical Decisions in Experiment 3 With Mean Standard Errors

\begin{tabular}{|c|c|c|c|c|c|}
\hline \multirow[b]{2}{*}{ Probe Type } & \multicolumn{2}{|c|}{$\begin{array}{c}\text { Related } \\
\text { Prime } \\
\left(\left[\mathrm{ko}_{\mathrm{m}}^{\mathrm{n}}\right]\right)\end{array}$} & \multicolumn{2}{|c|}{$\begin{array}{c}\text { Unrelated } \\
\text { Prime } \\
\left(\left[\mathrm{mæ}_{\mathrm{p}}^{\mathrm{t}}\right]\right)\end{array}$} & \multirow{2}{*}{$\begin{array}{l}\text { Priming } \\
\text { Effect }\end{array}$} \\
\hline & $M$ & $S E$ & $M$ & $S E$ & \\
\hline \multicolumn{6}{|c|}{ Noncoronal (e.g., сомB) } \\
\hline RT & 660 & 7.68 & 683 & 7.53 & 23 \\
\hline Accuracy rate & 96 & 1.0 & 92 & 1.37 & 4 \\
\hline \multicolumn{6}{|l|}{ Coronal (e.g., CONE) } \\
\hline RT & 681 & 7.86 & 679 & 7.23 & 3 \\
\hline Accuracy rate & 92 & 1.35 & 92 & 1.33 & 0 \\
\hline
\end{tabular}


half in rate, intonation, and speech and recording quality. The same lexical decision probes as those used in Experiment 1 were used in combination with the same prime tokens (e.g., labialized cone) in Experiment 3 to recreate the original design. All other stimulus, procedure, and design details were identical to those employed in Experiment 1 .

\section{Results and Discussion}

The overall results of Experiment 3 are summarized in Table 5. These data were prepared in the same manner as the data from Experiment 1. Two participants and two items were dropped from the analyses on the basis of overall performance on associated lexical decision trials that did not meet the inclusion requirement of $85 \%$ accuracy.

Planned contrast analyses revealed a clear pattern of priming effects. Analyses of reaction time data demonstrated a significant $23-\mathrm{msec}$ priming effect for the labial interpretation of primes [e.g., СОмB; $t_{1}(35)=1.8, p<.05$; $t_{2}(45)=1.7, p<.05$ ] but no significant priming for their coronal interpretations [e.g., CONE; $t_{1}(35)<.01, p>.05$; $\left.t_{2}(45)=0.1, p>.05\right]$. The results of the accuracy analyses followed a similar pattern, with contrast analyses showing significant priming for the labial interpretation of primes $\left[t_{1}(35)=2.1, p<.05 ; t_{2}(45)=1.7, p<.05\right]$, but not for the coronal interpretation of the same primes $\left[t_{1}(35)=.02, p>.05 ; t_{2}(45)=0.1, p>.05\right]$.

In general, the responses in Experiment 3 were slower than those in Experiment 1. This may be due, in part, to some relative unnaturalness in the cross-spliced stimuli used in this experiment. However, the fact that this slowing trend is consistent across control conditions suggests that naturalness effects cannot account for the specific pattern of priming found in this experiment.

Experiments 1 and 2 established that the same set of tokens of assimilated speech support both left-to-right and right-to-left context effects in speech perception. The contrast between the results of Experiments 3 and 1 further establishes the importance of context in the processing of assimilated speech. Indeed, these results, considered in conjunction with earlier work using very similar stimuli, show that three different postassimilation contexts produce three different patterns of priming. Gow (2002) found that when postassimilation context is removed, listeners access both labial and coronal interpretations of assimilated segments (COMB and CONE). In Experiment 1, labial context led to the access of the coronal alternative (CONE), and in Experiment 3 coronal context led to the access of the labial alternative (COMB).

The primary purpose of Experiment 3 was to determine whether these effects are the result of perceptual or knowledge-driven mechanisms. The results of this experiment are clearly consistent with the predictions of the perceptual accounts. The perceptual grouping explanation would be that strong labial cues associated with the onset of the context item (e.g., dents) attract evidence of labiality away from the assimilated segment, leaving only evidence of labiality to map onto the final segment of the prime word (COMB). The perceptual contrast account pro- vides an alternative explanation of this result. If assimilated segments have spectral characteristics that are intermediate between those of coronals and those of labials, exaggerating the perceptual differences between the assimilated segment and the coronal would make the assimilated segment sound more labial.

The knowledge-driven accounts of Lahiri and MarslenWilson (1991) or Gaskell and Marslen-Wilson (Gaskell et al., 1995; Gaskell \& Marlsen-Wilson, 1996, 1998, 2001) cannot explain these results. In English, labial segments do not undergo coronal assimilation. This means that listeners never experience speech in which a segment with a mixture of labial and coronal properties followed by a coronal is underlyingly labial. Listeners have no linguistic knowledge or experience to make the necessary phonological or phonetic inference to produce this result. Listeners should treat this context as being equivalent to the no-context condition explored in Gow (2002) and should access both coronal and labial interpretations (CONE and $\mathrm{COMB})$ of the perceptually ambiguous primes.

\section{GENERAL DISCUSSION}

The results reported here provide the basis for a more complete characterization of the computational problem posed by the recognition of assimilated speech. I will argue that assimilation poses a feature-parsing problem for listeners by introducing a nonlinear mapping between cues and segments and will suggest that the context effects that have been shown in the recognition of assimilated speech are best understood as the results of a general auditory cue grouping process that recovers the mapping.

\section{Acoustic Factors and Context Effects in the Perception of Assimilated Speech}

The results reported here reveal two important aspects of assimilation. The results of Experiments 1 and 2 demonstrated that a single assimilated segment can encode information that both allows listeners to recover its underlying form through an interaction with subsequent context and facilitates the perception of that context. Both pieces of information appear to be encoded in the fine phonetic detail of these segments. Listeners do not access coronal forms when an item such as ripe is followed by a labial context that could have transformed an underlying coronal (e.g., right) into a labial (Gaskell \& Marslen-Wilson, 2001; Gow, 2002). Moreover, Experiment 2 demonstrated that listeners do not show facilitated monitoring for labial targets when they are preceded by labial contexts, as opposed to labialized coronal contexts. The notion that one acoustic cue can simultaneously offer information about two segments is not new. Coarticulation is, by definition, the blending of two segments. The transitions between segments, such as the vocalic interval immediately before a stop closure, are a rich source of information about both adjacent segments (Strange, 1987). In the case of partial place assimilation, acoustic, aerodynamic, and articula- 
tory evidence all converge to demonstrate that assimilated segments combine elements of the assimilated and assimilating segment.

The other critical property of assimilation has to do with processing. The present results demonstrate that a single token of assimilated speech heard in context can participate in simultaneous progressive (Experiment 2) and regressive (Experiments 1 and 3 ) context effects. Although counterintuitive, there have been other demonstrations of similar bidirectional context effects in the processing of nonassimilated speech (see Mann \& Repp, 1981; Repp, 1978, 1983; Whalen, 1989). As in the case of assimilation, these effects tend to be strongest when one segment is phonetically ambiguous or intermediate between other categories. This parallel raises the possibility that the context effects observed here reflect a general perceptual or phonetic process that is not specific to the processing of lawful assimilation.

\section{Do Listeners Parse Feature Cues?}

The complex correspondence between temporally dispersed and often overlapping distributions of feature cues in the speech signal and sequential discrete phonemic representations suggests that listeners parse features. The more immediate question is whether that process is responsible for the context effects that have been shown in the processing of assimilated speech.

The present work constrains the description of the processing mechanism responsible for producing these context effects in two ways. First, it suggests that the mechanism is not derived from experience with specific assimilation phenomena. In Experiment 3, listeners hearing assimilated segments with acoustic properties intermediate between those of coronals and labials (e.g., cone pronounced $\left.\left[\mathrm{ko}_{\mathrm{m}}^{\mathrm{n}}\right]\right)$ accessed the labial interpretation ( $\mathrm{comb}$ ) when the next segment was coronal. Coronal-to-labial assimilation does not occur in English, and so listeners would have reason to infer that the underlying segment is labial. This rules out phonological inference (Gaskell \& Marslen-Wilson, $1996,1998,2001)$ as an explanation, because there is no basis for making this inference. Finally, it cannot be explained by underspecification theory (Lahiri \& MarslenWilson, 1991), because labial place is fully specified in English. The claim that familiarity with a specific phonological process plays a role in producing context effects in the processing of assimilated speech is further undermined by evidence that English speakers show context effects in the perception of an unfamiliar assimilation process (Hungarian voicing assimilation), whereas Korean speakers fail to show analogous context effects in the perception of a familiar, productive Korean place assimilation process (Gow \& Im, 2001).

Although the results of Experiment 3 are inconsistent with the predictions of models that rely on listeners' familiarity with a specific phonological process, they may be consistent with the predictions of another class of models that rely on learning. Nearey $(1990,1997)$ and Smits (2001a, 2001b) present pattern recognition models of phoneme perception that have been developed to address context effects in the perception of coarticulated speech. In principle, both of these models might account for the present results, given the simplifying assumption that the place of the assimilated and the context segments are respectively cued primarily by two cues, such as the value of $F 2$ at the offset of the assimilated stop and the onset value of $F 2$ for the context segment. Within both models, the categorization boundary for interpreting the place of the assimilated segment on the basis of $F 2$ in an appropriate (i.e., noncoronal) context would shift on the basis of experience with assimilation, providing a potential account for the results of Experiment 1. Furthermore, in both models, shifting the criterion in this context would also lead to a shift in the criterion applied in the noncoronal context in a direction that might explain the results of Experiment 3. This extrapolation from work on coarticulation suggests that these pattern recognition models may be profitably applied to understand assimilation context effects. Clearly, future work should explore assimilation directly, using these models.

The bidirectionality of assimilation context effects suggests another constraint that may help us understand the context effects shown across the present set of experiments. Although it is possible that regressive and progressive context effects are produced by independent mechanisms, the rule of parsimony argues for an account that explains both effects with a common mechanism. Like the pattern recognition models of Nearey $(1990,1997)$ and Smits (2001a, 2001b), contrast effects provide an elegant account of the regressive processing effects shown in Experiments 1 and 3. Maximizing the perceptual contrast between a segment that is intermediate between a coronal and a labial and its labial context would clearly enhance the coronality of the ambiguous segment in Experiment 1 . Similarly, enhancing the perceptual contrast between the same ambiguous segment and its coronal context in Experiment 3 would make the ambiguous segment sound more labial. However, perceptual contrast accounts cannot explain the progressive context effects shown in Experiment 2. Onset segments tend to be highly recognizable and acoustically and perceptually salient (Gow \& Gordon, 1995; Manuel, 1991; Stevens, 1998). As such, they may be viewed as good exemplars of their categories. If contrast effects play a role in the perception of context, a labialized coronal should make a subsequent labial sound less like an assimilated segment. This would shift the percept of the labial, making it a poorer exemplar. Evidence from studies of the speeded categorization of voiceless stops with exaggerated voicelessness (Miller, 2001) suggests that this would not lead to faster responses. Similarly, the pattern recognition models of Nearey (1990, 1997) and Smits (2001a, 2001b) do not appear to provide a basis for understanding the progressive context effects found in Experiment 2.

The feature-cue-parsing account of context effects respects both of the critical constraints suggested by the data. It does not depend on experience with a specific assimilation phenomenon. Auditory grouping is a fundamental perceptual process with applications to the perception of both linguistic and nonlinguistic stimuli. Although 
linguistic experience shapes phonetic and lexical inventories that may play a top-down role in some grouping processes (Bregman, 1990), basic grouping phenomena need not rely on experience with assimilation.

The feature-parsing account also explains how progressive and regressive context effects can result from a single process. The notion that progressive and regressive context effects can simultaneously play a role in the processing of adjacent segments is counterintuitive. This combination of context effects is less paradoxical, though, if both effects are the result of a single act of perceptual organization taking place in a buffer, such as echoic memory (Darwin, Turvey, \& Crowder, 1972).

The notion that cues are grouped within such a buffer is consistent with the finding that listeners perceive geminate stop pairs in $\mathrm{VC}-\mathrm{CV}$ sequences as a single segment when closure intervals are less than 200 msec (Pickett \& Decker, 1960; Repp, 1978). This cutoff point corresponds to the estimated size of this buffer over which listeners group a range of linguistic and nonlinguistic acoustic events (Cowan, 1984). In related work, Repp $(1978,1983)$ found evidence of bidirectional context effects in the perception of place in heterorganic $\mathrm{VC}-\mathrm{CV}$ stimuli that disappear when closure duration is greater than $200 \mathrm{msec}$.

Repp, Liberman, Eccardt, and Pesetsky (1978) have provided evidence of a nonassimilatory analogue to assimilatory context effects. They found that manipulations of the silent interval between the words gray and ship in the phrase Did anyone see the gray ship? could lead listeners to perceive the phrase as gray chip or great ship. Moreover, manipulations of frication duration at the onset of chip in the phrase gray chip lead listeners to perceive the phrase as great ship. Grossberg and Meyers (2000) demonstrated that this effect and other related results could be modeled in network simulations in which the phonemic interpretation of phonetic features is influenced by a general bias toward identifying the largest possible item at higher levels of representation. This is a grouping mechanism comparable to the schema-based auditory grouping mechanisms described by Bregman (1990) and motivated by research with nonlinguistic stimuli by Watson, Kelly, and Wroton (1976).

In summary, in this work, I have examined the perceptual process of mapping between the features encoded in assimilated segments and abstract representations of discrete segment sequences in connected speech. I have argued that place-assimilated segments encode two places of articulation and that listeners employ a variety of feature-parsing mechanisms to correctly align recovered features with segments. Feature parsing is a fundamental but relatively unexplored component of word recognition. It is hoped that future research will expand our understanding of this process and its role in the perception of modified and unmodified speech.

\section{REFERENCES}

Bailey, P. J. \& Summerfield, Q. (1980). Information in speech: Some observations on the perception of [s]- stop clusters. Journal of Experimental Psychology: Human Perception \& Performance, 6, 536-563.
BARry, M. C. (1985). A palatographic study of connected speech processes. In Cambridge papers in phonetics and experimental linguistics (Vol. 4., pp. 1-16). University of Cambridge, Department of Linguistics.

BÉKÉSY, G. von (1967). Sensory inhibition. Princeton, NJ: Princeton University Press.

Best, C. T., Morrongiello, B., \& Robson, R. (1981). Perceptual equivalence of acoustic cues in speech and nonspeech perception. Perception \& Psychophysics, 29, 191-211.

Boardman, I., Grossberg, S., Myers, C., \& Cohen, M. (1999). Neural dynamics of perceptual order and context effects for variable-rate speech syllables. Perception \& Psychophysics, 61, 1477-1500.

Bregman, A. S. (1978). Auditory streaming: Competition among alternative organizations. Perception \& Psychophysics, 23, 391-398.

Bregman, A. S. (1990). Auditory scene analysis. Cambridge, MA: MIT Press.

Bregman, A. S., \& Rudnicky, A. (1975). Auditory segregation: Stream or streams? Journal of Experimental Psychology: Human Perception \& Performance, 1, 263-267.

Browman, C. P., \& Goldstein, L. (1990). Articulatory gestures as phonological units. Phonology, 6, 201-231.

Coenen, E., Zwitserlood, P., \& Bölte, J. (2001). Variation and assimilation in German: Consequences for lexical access and representation. Language \& Cognitive Processes, 16, 535-564.

Cohen J. D., MacWhinney B., Flatt M., \& Provost, J. (1993). PsyScope: An interactive graphic system for designing and controlling experiments in the psychology laboratory using Macintosh computers. Behavior Research Methods, Instruments, \& Computers, 25, 257-271.

Cowan, N. (1984). On short and long auditory stores. Psychological Bulletin, 96, 341-370.

Darwin, C. J., Turvey, M. T., \& Crowder, R. G. (1972). An auditory analog of the Sperling partial report procedure: Evidence for brief auditory storage. Cognitive Psychology, 3, 255-267.

Francis,W. N., \& KuČera, H. (1982). Frequency analysis of English usage. Boston, MA: Houghton Mifflin Co.

Gaskell, M. G., Hare, M., \& Marslen-Wilson, W. D. (1995). A connectionist model of phonological representation in speech perception. Cognitive Science, 19, 407-439.

Gaskell, M. G., \& Marslen-Wilson, W. D. (1996). Phonologicalvariation and inference in lexical access. Journal of Experimental Psychology: Human Perception \& Performance, 22, 144-158.

Gaskell, M. G., \& Marslen-Wilson, W. D. (1998). Mechanisms of phonological inference in speech perception. Journal of Experimental Psychology: Human Perception \& Performance, 24, 380-396.

Gaskell, M. G., \& MARslen-Wilson, W. D. (2001). Lexical ambiguity resolution and spoken word recognition: Bridging the gap. Journal of Memory \& Language, 44, 325-349.

GoLDSMITH, J. (1976). Overview of autosegmental phonology. Linguistic Analysis, 2, 23-68.

Gow, D. W. (2001). Assimilation and anticipation in continuous spoken word recognition. Journal of Memory \& Language, 45, 133-159.

Gow, D. W. (2002). Does English coronal place assimilation create lexical ambiguity? Journal of Experimental Psychology: Human Perception \& Performance, 28, 163-179.

Gow, D. W. (2003). The acoustic manifestation of coronal to labial place assimilation in English. Manuscript in preparation.

Gow, D. W., \& GorDON, P. C. (1995). Lexical and prelexical influences on word segmentation: Evidence from priming. Journal of Experimental Psychology: Human Perception \& Performance, 21, 344-359.

Gow, D. W., \& Hussami, P. (1999, November). Acoustic modification in English place assimilation. Paper presented at the meeting of the Acoustical Society of America, Columbus, $\mathrm{OH}$.

Gow, D. W., \& IM, A. (2001, November). Perceptual effects of native and non-native assimilation. Paper presented at the 42nd Annual Meeting of the Psychonomic Society, Orlando, FL.

Grossberg, S., \& Myers, C. W. (2000). The resonant dynamics of speech perception: Interword integration and duration-dependent backward effects. Psychological Review, 107, 735-767.

Hartline, H. F., \& RatCLIFF, F. (1957). Spatial summation of inhibitory influences in the eye of limulus, and the mutual interaction of receptor units. Journal of General Physiology, 40, 357-376.

Hodgson, P., \& Miller, J. (1996). Internal structure of phonetic cate- 
gories: Evidence for within category trading relations. Journal of the Acoustical Society of America, 100, 565-576.

Holst, T., \& Nolan, F. (1995). The influence of syntactic structure on [s] to [ $\beta]$ assimilation. In B. Connell \& A. Arvanti (Eds.), Phonology and phonetic evidence: Papers in laboratory phonologyIV. (pp. 315333). Cambridge: Cambridge University Press.

Holt, L. L., LotTo, A. J., \& KLuender, K. R. (2001). Influence of fundamental frequency on stop-consonant voicing perception: A case of learned covariation or auditory enhancement? Journal of the Acoustical Society of America, 109, 764-774.

JuleSz, B., \& HiRSH, I. J. (1972). Visual and auditory perception: An essay of comparison. In E. E. David \& P. B. Denes (Eds.), Human communication: A unified view (pp. 283-340). New York: McGraw Hill.

JuN, J. (1996). Place assimilation is not the result of gestural overlap. Phonology, 13, 337-407.

Kenstowicz, M. (1994). Phonology in generative grammar. Cambridge, MA: Blackwell.

Kerswill, P. E. (1985). A sociophonetic study of connected speech processes in Cambridge English: An outline and some results. Cambridge Papers in Phonetics \& Experimental Linguistics, 4, 1-39.

KoffKA, K. (1935). Principles of Gestalt psychology. New York: Hartcourt \& Brace.

Kuehn, D. P., \& Moll, K. L. (1972). Perceptual effects for forward coarticulation. Journal of Hearing \& Speech Research, 15, 654-664.

LAhiri, A., \& MARSLEN-WiLson, W. D. (1991). The mental representation of lexical form: A phonological approach to the recognition lexicon. Cognition, 38, 245-294.

LaRiviere, C. J., Winitz, H., \& Herriman, E. (1975). The distribution of perceptual cues in English prevocalic fricatives. Journal of Speech \& Hearing Research, 3, 613-622.

LeHISTe, I., \& Shockey, L. (1972). On the perception of coarticulation effects in English CVC syllables. Journal of Speech \& Hearing Research, 15, 500-506.

LotTo, A. J., \& Kluender, K. R. (1998). General contrast effects in speech perception: Effect of preceding liquid on stop consonant identification. Perception \& Psychophysics, 60, 602-619.

Lotto, A. J., Kluender, K. R., \& Holt, L. L. (1997). Perceptual compensation for coarticulation by Japanese quail (Coturnix coturnix japonica). Journal of the Acoustical Society of America, 102, 1134-1140.

MANN, V. A., \& REPP, B. H. (1981). Influence of preceding fricative on stop consonant perception. Journal of the Acoustical Society of America, 69, 548-558.

MAnuel, S. Y. (1991). Some phonetic bases for the relative malleability of syllable-final versus syllable initial consonants. Proceedings of the 12th International Congress of Phonetic Sciences, 5, 118-121.

Marslen-Wilson, W. D. (1987). Functional parallelism is spoken word-recognition. Cognition, 25, 71-102.

Martin, J. G., \& Bunnell, H. T. (1981). Perception of anticipatory coarticulation effects. Journal of the Acoustical Society of America, 69, 559-567.

McClelland, J. L., \& Elman, J. L. (1986). Interactive processes in speech recognition: The TRACE model. In J. L. McClelland \& D. E. Rumelhart (Eds.), Parallel distributed processing: Explorations in the microstructure of cognition ( pp. 58-121). Cambridge, MA: MIT Press, Bradford Books.

MCNALly, K. A., \& Handel, S. (1977). Effect of element composition on streaming and ordering of repeating sequences. Journal of Experimental Psychology: Human Perception \& Performance, 3, 451-460.

Miller, J. L. (2001). Mapping from acoustic signal to phonetic category: Internal category structure, context effects and speeded categorization. Language \& Cognitive Processes, 16, 683-690.

NeAREY, T. M. (1990). The segment as a unit of speech perception. Journal of Phonetics, 18, 347-373.

NeAREY. T. M. (1997). Speech perception as pattern recognition. Journal of the Acoustical Society of America, 101, 3241-3254.

Nolan, F., Holst, T., \& Kuhnert, B. (1996). Modeling [s] to [J] accommodation in English. Journal of Phonetics, 24, 113-137.

NorRIS, D. G. (1994). Shortlist: A connectionist model of continuous speech recognition. Cognition, 52, 189-234.
Norris, D. G., McQueen, J., \& Cutler, A. (2000). Merging information in speech recognition: Feedback is never necessary. Behavioral \& Brain Sciences, 23, 299-370.

Ostreicher, H. J., \& Sharf, D. J. (1976). Effects of coarticulation on the identification of deleted consonant and vowel sounds. Journal of Phonetics, 4, 285-301.

Parker, E. M., Diehl, R. L., \& Kluender, K. R. (1986). Trading relations in speech and nonspeech. Perception \& Psychophysics, 39, 129-142.

Petersen, G. E., \& Barney,H. (1952). Control methods used in a study of the vowels. Journal of the Acoustical Society of America, 24, 1751843.

Pickett, J. M., \& Decker, L. R. (1960). Time factors in perception of a double consonant. Language \& Speech, 3, 11-17.

PitT, M. A., \& McQueen, J. M. (1998). Is compensation for coarticulation mediated by the lexicon? Journal of Memory \& Language, 39, 347-370.

REPP, B. H. (1978). Perceptual integration and differentiation of spectral cues for intervocalic stop consonants. Perception \& Psychophysics, 24, 471-485.

REPP, B. H. (1982). Phonetic trading relations and context effects: New experimental evidence for a speech mode of perception. Psychological Bulletin, 92, 81-110.

REPP, B. H. (1983). Bidirectional contrast effects in the perception of VC-CV sequences. Perception \& Psychophysics, 33, 147-155.

Repr, B. H., Liberman, A. M., Eccardt, T., \& Pesetsky, D. (1978). Perceptual integration of acoustic cues for stop, fricative and affricate manner. Journal of Experimental Psychology: Human Perception \& Performance, 4, 621-637.

Rosenthal, R, \& Rosnow, R. L. (1985). Contrastanalysis. Cambridge: Cambridge University Press.

Saffran, J. R. Aslin. R. N., \& Newport, E. L. (1996). Statistical learning by 8-month-old infants. Science, 274, 1926-1928.

Silverman, J., \& JUN, J. (1994). Aerodynamic evidence for articulatory overlap in Korean. Phonetica, 51, 210-220.

Sinnott, J. M., \& SAporita, T. A. (2000). Differences in American English, Spanish, and monkey perception of the say-stay trading relation. Perception \& Psychophysics, 62, 1312-1319.

SMiтs, R. (2001a). Evidence for hierachical categorization of coarticulated phonemes. Journal of Experimental Psychology: Human Perception \& Performance, 27, 1145-1162.

SMITS, R. (2001b). Hierarchical categorization of coarticulated phonemes: A theoretical analysis. Perception \& Psychophysics, 63, 1109. 1139.

Stevens, K. (1998). Acoustic phonetics. Cambridge, MA: MIT Press. STRANGE, W. (1987). Information for vowels in formant transitions. Journal of Memory \& Language, 26, 550-557.

Summerfield, Q., \& Haggard, M. (1977). On the dissociation of spectral and temporal cues to the voicing distinction in initial stop consonants. Journal of the Acoustical Society of America, 62, 435-448.

Treisman, M. (1999). There are two types of psychometric function: A theory of cue combination in the processing of complex stimuli with implications for categorical perception. Journal of Experimental Psychology: General, 128, 517-546.

Warren, R. (1985). Criterion shift and perceptual homeostasis. Psychological Review, 92, 574-584.

Watson, C. S., Kelly, W. J., \& Wroton, H. W. (1976). Factors in the discrimination of tonal patterns: II. Selective attention and learning under various levels of uncertainty. Journal of the Acoustical Society of America, 60, 1176-1186.

WertheIMER, M. (1938). Laws of organization in perceptual forms. In W. D. Ellis (Ed.), A sourcebook of Gestalt psychology (pp. 71-88). London: Kegan Paul, Trench, \& Trubner. (Original work published 1923)

Whalen, D. H. (1989). Vowel and consonant judgments are not independent when cued by the same information. Perception \& Psychophysics, 46, 284-292.

Yeni-Komshian, G. H., \& Soli, S. D. (1981). Recognition of vowels from information in fricatives: Perceptual evidence of fricative-vowel coarticulation. Journal of the Acoustical Society of America, 70, 966975. 


\section{APPENDIX A \\ Stimuli Employed in Experiments 1 and 2}

Italics indicate the prime item in Experiment 1. Note that the final coronal segment in each prime underwent labial assimilation. Related lexical decision probes appear in parentheses. Target phonemes for the monitoring task employed in Experiment 2 are indicated by underlining. In the second experiment, there was a cross-splice made just prior to the target phoneme, and three alternate versions of the first section of the sentence were formed by replacing the italicized word with the two words shown in parentheses or the assimilated form of the first word shown in parentheses that approximated the second word shown in parentheses.

1. She carefully selected the right beets for the recipe. (RIGHT/RIPE)

2. The sound of the $\cot$ broke the silence. (СОT/СOP)

3. The plastic cone bent easily. (CONE/COMB)

4. She saw the hen break away. (HEN/HEM)

5 . The museum curator found the loon boxed in a store room. (LOON/LOOM)

6 . His noontime run broke up the day. (RUN/RUM)

7. They want the one that will coat best. (COAT/COPE)

8. She was careful not to let her $c u t \underline{\text { bang the chair. (CUT/CUP) }}$

9. The heat blazed out of the furnace. (HEAT/HEAP)

10. She thought he was the sane boy there. (SANE/SAME)

11. He gave the phone back to the owner. (PHONE/FOAM)

12. His old cat blew off the chair in the hurricane. (CAT/CAP)

13. The old mat bends where it was folded. (MAT/MAP)

14. Parts of the crowd started to seat $\underline{\text { both }}$ ways. (SEAT/SEEP)

15. The group was already that tight $\underline{\text { back in }}$ grade school. (TIGHT/TYPE)

16. The researcher wondered why the clan brought itself into view. (CLAN/CLAM)

17. They drew the line big enough so it was seen. (LINE/LIME)

18. His famous hit brought him a lot of attention. (HIT/HIP)

19. The new suit boosts his reputation. (SUIT/SOUP)

20. The scan bears close examination. (SCAN/SCAM)

21. He had a little gin break after work. (GIN/GYM)

22. The young teen beat all of the competition. (TEEN/TEAM)

23. All of this sleet brings changes. (SLEET/SLEEP)

24. He knew he had the rat beat at that point.(RAT/RAP)

25 . They need to $r i d$ pals from the audience. (RID/RIB)

26. They made the lad pay a ticket. (LAD/LAB)

27. There was a small bean placed behind the sink. (BEAN/BEAM)

28. The man who made the bid poured the wine. (BID/BIB)

29. Doing the scene posed serious difficulties. (SCENE/SEAM)

30. They said that bun placed first in the contest. (BUN/BUM)

31. The few who recognized the screen paid little attention to it. (SCREEN/SCREAM)

32. The sun poured in this morning. (SUN/SUM)

33. The grad played well on the screen. (GRAD/GRAB)

34. The $c a d$ pinned her in traffic. (CAD/CAB)

35. Twisting it a $t a d$ placed it in a good location. (TAD/TAB)

36. The diner wanted the $\operatorname{cod}$ passed to him. (COD/COB)

37. The little nod pleased the designer's eye. (NOD/KNOB)

38. The road passed from one town to the next. (ROAD/ROBE)

39. The flood plagued him for days. (FLOOD/FLUB)

40. Someone had the load propped up on a stand. (LOAD/LOBE)

41. They let the bride prod them into action. (BRIDE/BRIBE) 
42. They were to wed pairs together. (WED/WEB)

43. That stud proved to be useful. (STUD/STUB)

44. The $d u d$ paused because of its bad quality. (DUD/DUB)

45. I like to keep the curd plain. (CURD/CURB)

46. The lewd part was the last straw. (LEWD/LUBE)

47. The sod paused at the top of the hill. (SOD/SOB)

48. The boys tried past resolutions. (TRIED/TRIBE)

\section{APPENDIX B \\ Stimuli Used in Experiment 3}

Prime items ending in labial assimilated underlying coronals are shown in italics. Related lexical decision probes appear in parentheses. Double slashes indicate the location of the cross-splice. The portion of the sentence before the cross-splice was taken directly from stimulus tokens employed in Experiments 1 and 2.

1. She carefully selected the right // time for the project. (RIGHT/RIPE)

2. The sound of the cot// droned through the night. (СОT/COP)

3. The plastic cone // dents easily. (CONE/COMB)

4. She saw the hen// trail off to the side. (HEN/HEM)

5 . The museum curator found the loon //down in a store room. (LOON/LOOM)

6. His noontime run // took up most of the day. (RUN/RUM)

7. They want the one that will coat // twice as well. (COAT/COPE)

8. She was careful not to let her $c u t / /$ touch the chair. (CUT/CUP)

9. The heat // drifts out of the furnace. (HEAT/HEAP)

10. She thought he was the sane // dude she'd always known. (SANE/SAME)

11. He gave the phone // to the owner. (PHONE/FOAM)

12. His old cat // drove him crazy. (CAT/CAP)

13. The old mat // tore where it was folded. (MAT/MAP)

14. Parts of the crowd started to seat // towards two directions. (SEAT/SEEP)

15. The group was already that tight // during grade school. (TIGHT/TYPE)

16. The researcher wondered why the clan // trapped itself like that. (CLAN/CLAM)

17. They drew the line // tall enough so it was seen. (LINE/LIME)

18. His famous hit// turned into a sensation. (HIT/HIP)

19. The new suit // tamed his reputation. (SUIT/SOUP)

20. The scan // did little damage. (SCAN/SCAM)

21. He had a little $g$ in // date after work. (GIN/GYM)

22. The young teen // tracked all of the changes. (TEEN/TEAM)

23. All of this sleet // does make you wonder. (SLEET/SLEEP)

24. He knew he had the rat// turned over to someone else. (RAT/RAP)

25. They need to rid // drunks from the audience. (RID/RIB)

26. They made the lad // treat mice better. (LAD/LAB)

27. There was a small bean // dropped behind the sink. (BEAN/BEAM)

28. The man who made the bid// drank the wine. (BID/BIB)

29. Doing the scene // drudged up memories. (SCENE/SEAM)

30. They said that bun // dropped onto the sidewalk. (BUN/BUM)

31. The few who recognized the screen // told us who made it. (SCREEN/SCREAM)

32. The sun // dipped in the evening. (SUN/SUM)

33. The $\mathrm{grad} / /$ tells us he was on his feet. (GRAD/GRAB)

34. The $c a d / /$ tipped over. (CAD/CAB)

35. Twisting it a tad// tuned it perfectly. (TAD/TAB) 
APPENDIX B (Continued)

36. The diner wanted the $\operatorname{cod} / /$ tossed to him. (COD/COB)

37. The little nod // tricked him. (NOD/KNOB)

38. The road // twists all over the place. (ROAD/ROBE)

39. The flood // drew attention to the small town. (FLOOD/FLUB)

40. Someone had the load// dropped on a stand. (LOAD/LOBE)

41. They let the bride // draw them into action. (BRIDE/BRIBE)

42. They were to wed // teams together. (WED/WEB)

43. That stud// dulled as time went on. (STUD/STUB)

44. The $d u d / /$ trilled because of its bad quality. (DUD/DUB)

45. I like to keep the curd // dry. (CURD/CURB)

46. The lewd // deal was the last straw. (LEWD/LUBE)

47. The sod // tumbled from the top of the hill. (SOD/SOB)

48. The boys tried// trained dogs in the show. (TRIED/TRIBE)

(Manuscript received October 5, 2001;

revision accepted for publication October 9, 2002.) 